\section{Intestinal Sugar Absorption and Phosphate Metabolism}

IT has been shown in previous work that the selective absorption of sugars from the intestine of rats is strongly affected by iodoacetate ${ }^{1}$ : after administration of this poison all hexoses are absorbed at the same rate. This has been interpreted as due to the fact that phosphorylation of sugars accelerates their absorption. It was shown that extracts of intestinal mucosa phosphorylize those sugars which are selectively absorbed; furthermore, that iodoacetate inhibits this phosphorylation ${ }^{2}$ and that organic phosphate in the intestinal mucosa increases during sugar absorption ${ }^{3}$.

It has now been found that absorption of any monosaccharide from isolated loops of the small intestine causes inorganic phosphate to enter the intestine, whereas absorption of sodium chloride or amino-acids has no such effect. Sugars which are not selectively absorbed also increase intestinal phosphates, but the change of concentration with time is different; with glucose the intestinal phosphate content is maximal already after 15 minutes and then falls off to about zero in about $1 \frac{1}{2}$ hours, whereas with xylose it rises slowly to about the same level in 45 minutes. After iodoacetate administration this difference disappears, and the phosphate content of the intestine after $\mathbf{4 5}$ minutes is the same for xylose and glucose. Also after adrenalectomy the reabsorption of phosphate during glucose absorption is suppressed. Thus entry and reabsorption of phosphate seems related to the selective absorption of sugars.

Experiments on the role of various endocrine glands which control intestinal sugar absorption are at present being carried out. It is also hoped that future work along the same line may throw light on the problem of phosphate metabolism in the bones. The results will be published in detail later.

L. LASZT.

Physiological Laboratory,

University of Fribourg, Switzerland.

April 30.

1 Wilbrand, W, and Laszt, L, Biochem. Z, 259, 398 (1933).

2 Laszt, L., Biochem. Z., 276, 44 (1935).

${ }^{3}$ Laszt, L., and Süllmann, H., Biochem. Z., 278, 401 (1935)

\section{Effect of Inversion of a Small Piece from the Fruit-Body of Ganoderma lucidus (Leyss.) Karst. growing in situ on the Trunk of Casuarina equisetifolia}

BRACKET-SHAPED sporophores of Ganoderma lucidus were growing on the trunk of an old tree of Casuarina equisetifolia in the Royal Botanical Gardens, Sibpur (Calcutta) in front of the superintendent's quarters on the bank of the Ganges. From each of the two sporophores, one growing over the other (Fig. 1), a narrow sector was cut out almost in the middle and inserted (on September 6, 1939) in the inverted position, that is, with the porous surface upwards in the cavity thus produced. It was found that in the course of nine days regeneration of the hyphæ began by way of stitching from two sides (Fig. 1). A number of interwoven hyphæ developed between the

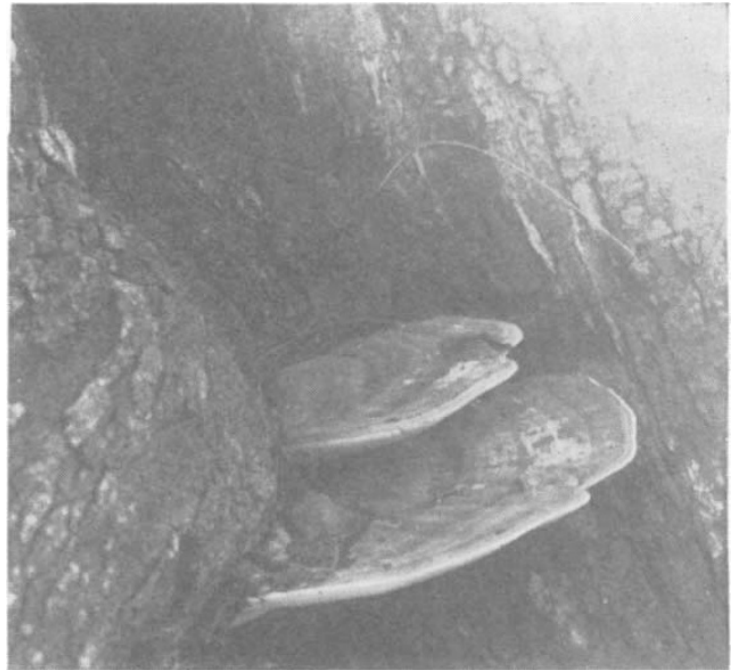

Fig. 1.

Two SPOROPHORES OF Ganoderma lucidus, ONE GROWING ABOVE THE OTHER ON THE TRUNK OF Casuarina equisetifolia.

old sporophore and the new prece. The hymenial surface of the specimens was perfectly white in
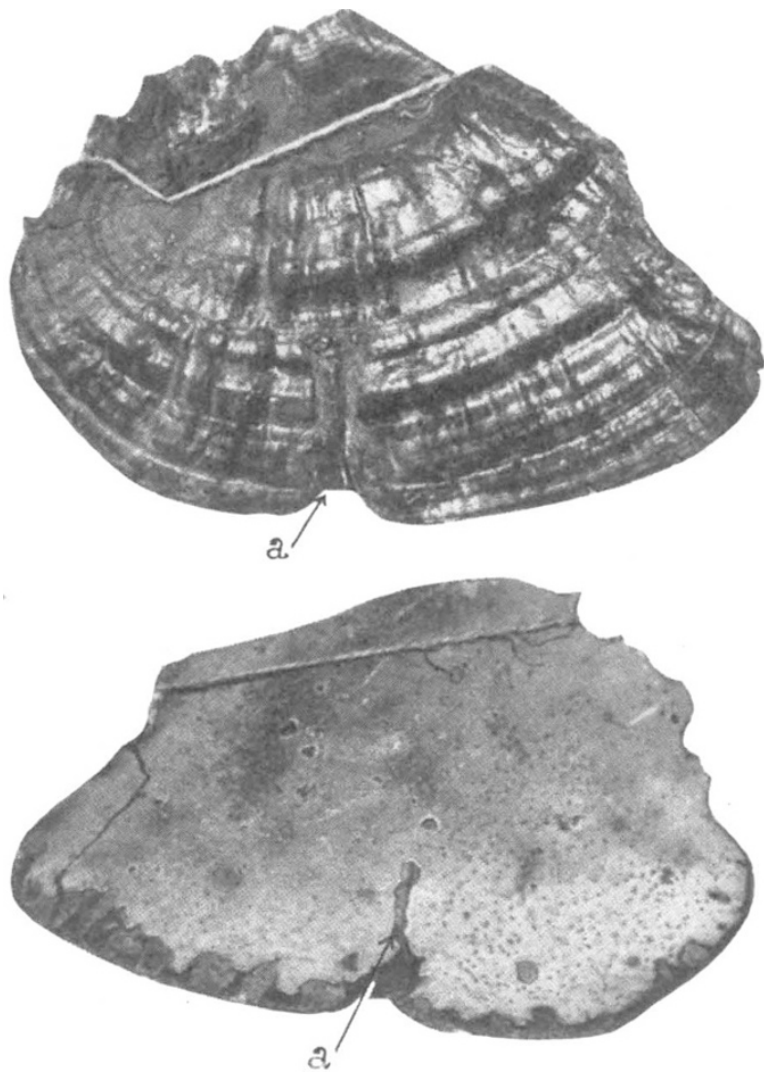

Fig. 2.

ABOVE-UPPER SURFACE OF THE SPOROPHORE OF Ganoderma lucidus SHOWING THE DEVELOPMENT OF LACCATE CRUST ON THE UPPER FACE OF THE CUT-OUT SECTOR AT $a$.

BELOW-HYMENIAL SURFACE OF THE SAME SHOWING FLANKING-OVER HYMENIAL GROWTH FROM TWO SIDES ON THE CRUST OF THE CUT-OUT SECTOR AT $a$. 